www.volsu.ru

DOI: https://doi.org/10.15688/jvolsu3.2017.2.7

UDC 332.146.2

LBC 65.049(2)

\title{
ON THE DEVELOPMENT OF PUBLIC-PRIVATE PARTNERSHIP IN THE CONTEXT OF REGIONAL ECONOMY (ON THE EXAMPLE OF REPUBLIC OF KALMYKIA)
}

\author{
Kermen M. Maksimova \\ Kalmyk State University named after B.B. Gorodovikov, Elista, Russian Federation
}

\begin{abstract}
Public-private partnership is a significant factor of socio-economic development of the territory, the widespread use of which should enhance the investment attractiveness of the region, increase revenues for the regional budget, as well as the implementation of socially significant investment projects in the Republic of Kalmykia.

The study found that today a public-private partnership is in the process of its formation in the Republic of Kalmykia. In the near future there is need to carry out substantial and systematic work on the development of partnership and improvement of regulatory legal base, regulating the issues of property rights, sharing risks and responsibility; the creation of a specialized structure, responsible for the development and coordination of the interaction between the state (municipal) agencies and private businesses; the training of highly qualified specialists among the employees of the regional and municipal levels, as well as the issue of financial security of projects.
\end{abstract}

Key words: public-private partnership, regional economy, investment projects, investment attractiveness, state and municipal management, private business.

УДК 332.146 .2

ББК 65.049(2)

\section{К ВОПРОСУ О РАЗВИТИИ ГОСУДАРСТВЕННО-ЧАСТНОГО ПАРТНЕРСТВА В УСЛОВИЯХ РЕГИОНАЛЬНОЙ ЭКОНОМИКИ (НА ПРИМЕРЕ РЕСПУБЛИКИ КАЛМЫКИЯ)}

\author{
Кермен Михайловна Максимова \\ Калмыцкий государственный университет им. Б.Б. Городовикова, г. Элиста, Российская Федерация
}

\footnotetext{
Аннотация. Государственно-частное партнерство представляет собой значимый фактор социальноэкономического развития территории, широкое применение которого должно способствовать повышению инвестиционной привлекательности региона, пополнению доходной части регионального бюджета, а также реализации социально значимых инвестиционных проектов в Республике Калмыкия.

Проведенное исследование выявило, что на сегодняшний день в республике государственно-частное - партнерство находится в процессе своего формирования. В ближайшее время предстоит существенная и 호 планомерная работа по его развитию и совершенствованию нормативно-правовой базы, регулирующей вопросы прав собственности, разделения рисков и ответственности; по созданию специализированной структуры, отвечающей за развитие и координацию взаимодействия государственных (муниципальных) структур и частного бизнеса; по подготовке высококвалифицированных специалистов среди служащих регионального и муниципального уровней, а также вопрос финансового обеспечения проектов.

Ключевые слова: государственно-частное партнерство, региональная экономика, инвестиционные проекты, инвестиционная привлекательность, государственное и муниципальное управление, частный бизнес.
} 
В основе комплексного развития института государственно-частного партнерства (далее - ГЧП) в субъектах Российской Федерации лежит успешное функционирование системы государственного и муниципального управления данным механизмом, которое способствует расширению возможности реализации инфраструктурных проектов на принципах ГЧП, а также повышает интерес частного сектора к проектам ГЧП в субъекте РФ.

В целях достижения поставленных задач в региональной политике целесообразно использовать:

- законодательную и институциональную инициативу, направленную на интеграцию социально-экономического пространства федерального округа и нацеленную на приоритетное развитие межрегиональных проектов ГЧП с концентрацией на данном направлении ресурсов всех уровней бюджетов;

- федеральные и региональные государственные программы, муниципальные программы, а также программы крупных компаний, ориентированные на применение ГЧП при реализации комплексного развития территории Республики Калмыкия;

- привлечение на осуществление инфраструктурных инвестиционных проектов как средств Инвестиционного фонда Российской Федерации, так и других институтов развития [2];

- создание особого института развития, учитывающего специфику региона.

Использование и реализация различных форм ГЧП в республике должно соответствовать положениям стратегических документов социально-экономического развития Российской Федерации и вместе с тем рационально сочетать региональные и отраслевые интересы.

В современной России полномочия между уровнями власти распределены таким образом, что развитие общественной инфраструктуры законодательно возложено на региональные государственные и муниципальные органы власти, для которых проблема нехватки бюджетных средств особенно актуальна.

В Республике Калмыкия текущее состояние таких объектов инфраструктуры, как дорожное хозяйство, жилищно-коммунальное хозяйство, электроэнергетика требует нема- лых финансовых вложений на их обновление и расширение. Низкое качество инфраструктуры резко снижает экономическую эффективность функционирования как частного, так и государственного секторов экономики $[1 ; 6]$.

Для бизнес-структур это может выражаться в росте себестоимости продукции, усложнении реализации новых проектов, возрастании эксплуатационных и других рисков.

Для республики это означает рост расходов на эксплуатацию инфраструктурных объектов по причине их материального и морального износа и снижения темпов роста налоговых поступлений. Создается угроза безопасности, в том числе экономической. Однако на сегодняшний день у республики, в условиях снизившихся доходных бюджетных поступлений, нет достаточного объема финансовых средств для инвестирования.

В этой связи возрастает необходимость взаимодействия государства с частным сектором, попытки найти соответствующие решения, позволяющие использовать капитал частного сектора для решения задач государственной политики. В этих условиях государственно-частное партнерство становится особенно важным инструментом создания объектов инфраструктуры общественного сектора.

В настоящее время в Республике Калмыкия реализуются пять проектов, предполагающих инвестирование в различных секторах экономики и находящихся на разных стадиях реализации. Несмотря на то что срок реализации двух из них закончился в 2016 г., ни один из этих проектов не стал полноценной практикой реализации государственно-частного партнерства. Рассмотрим проекты ГЧП более подробно в таблице.

Одним из наиболее важных вопросов является вопрос финансового обеспечения проектов ГЧП, который в значительной степени предопределяет экономическую эффективность и уровень инвестиционного потенциала. Любое вложение капитала требует его рационального, экономически выгодного инвестиционного размещения. В этой связи одним из первоочередных организационно-управленческих вопросов ГЧП является поиск оптимального решения по достижению баланса интересов между доходностью от вложенного капитала при существовании определенных 
Проекты государственно-частного партнерства, реализуемые на территории Республики Калмыкия

\begin{tabular}{|c|c|c|c|c|c|c|c|c|}
\hline $\begin{array}{c}\text { № } \\
\Pi / \Pi\end{array}$ & Инвестор & $\begin{array}{c}\text { Сфера деятель- } \\
\text { ности }\end{array}$ & Объем & $\begin{array}{c}\text { Срок } \\
\text { реализа- } \\
\text { ции }\end{array}$ & Размещение & $\begin{array}{c}\text { Стоимость } \\
\text { проекта }\end{array}$ & $\begin{array}{l}\text { Количе- } \\
\text { ство но- } \\
\text { вых ра- } \\
\text { бочих } \\
\text { мест } \\
\end{array}$ & $\begin{array}{c}\text { Выполнение } \\
\text { по состоянию } \\
\text { на } 01.012017 \text { г. }\end{array}$ \\
\hline 1 & $\begin{array}{l}\text { АО «Фалкон } \\
\text { Капитал» } \\
\text { («Falkon } \\
\text { Capitala.s.», } \\
\text { Чешская } \\
\text { Республика, } \\
\text { г. Прага, } \\
\text { ООО «АЛ- } \\
\text { ТЭН» }\end{array}$ & $\begin{array}{l}\text { Строительство } \\
\text { ветряных элек- } \\
\text { тростанций }\end{array}$ & $300 \mathrm{MBT}$ & $\begin{array}{c}2008- \\
2018 \text { гг. }\end{array}$ & $\begin{array}{l}\text { Республика } \\
\text { Калмыкия, } \\
\text { Приютнен- } \\
\text { ский район }\end{array}$ & $\begin{array}{c}11,04 \\
\text { млн руб. }\end{array}$ & 50 & $\begin{array}{l}\text { Завершены элек- } \\
\text { тромонтажные } \\
\text { работы по ре- } \\
\text { конструкции } \\
\text { подстанции ПС } \\
\text { «есчаная» }\end{array}$ \\
\hline 2 & $\begin{array}{l}\text { ООО «Кал- } \\
\text { мыцкий } \\
\text { бройлер» }\end{array}$ & $\begin{array}{l}\text { Строительство } \\
\text { производст- } \\
\text { венного ком- } \\
\text { плекса с замк- } \\
\text { нутым циклом } \\
\text { производства } \\
\text { мяса бройлеров }\end{array}$ & $\begin{array}{l}11,33 \text { тыс. т } \\
\text { в убойном } \\
\text { весе с пер- } \\
\text { спективой } \\
\text { до 20,0 } \\
\text { тыс. т в год }\end{array}$ & $\begin{array}{c}2011- \\
2017 \text { гг. }\end{array}$ & $\begin{array}{l}\text { Республика } \\
\text { Калмыкия, } \\
\text { Городови- } \\
\text { ковский } \\
\text { район }\end{array}$ & $\begin{array}{r}1577,8 \\
\text { млн руб. }\end{array}$ & 257 & $\begin{array}{l}\text { Проектно- } \\
\text { изыскательские } \\
\text { работы, подъ- } \\
\text { ездная дорога }\end{array}$ \\
\hline 3 & $\begin{array}{l}\text { Группа ком- } \\
\text { паний } \\
\text { «Продкон- } \\
\text { тракт» } \\
\text { ООО «Биф } \\
\text { Арт» }\end{array}$ & $\begin{array}{l}\text { Мясоперераба- } \\
\text { тывающий } \\
\text { комплекс по } \\
\text { откорму, убою } \\
\text { и первичной } \\
\text { переработке } \\
\text { скота }\end{array}$ & $\begin{array}{l}300 \text { голов в } \\
\text { день }\end{array}$ & $\begin{array}{c}2011- \\
2017 \text { Гг. }\end{array}$ & $\begin{array}{l}\text { Республика } \\
\text { Калмыкия, } \\
\text { Кетченеров- } \\
\text { ский район }\end{array}$ & $\begin{array}{c}\text { 4,6 } \\
\text { млрд руб. }\end{array}$ & $200-250$ & $\begin{array}{l}\text { Комплекс по об- } \\
\text { работке и хране- } \\
\text { нию мясной } \\
\text { продукции готов } \\
\text { на } 98 \text { \%. } \\
\text { Мясоперераба- } \\
\text { тывающий ком- } \\
\text { плекс готов на } \\
83 \text { \% }\end{array}$ \\
\hline 4 & $\begin{array}{l}\text { ЗАО «Био- } \\
\text { ресурс» }\end{array}$ & $\begin{array}{l}\text { Строительство } \\
\text { туристического } \\
\text { комплекса }\end{array}$ & $\begin{array}{l}\text { Создание } \\
\text { туристско- } \\
\text { рекреаци- } \\
\text { онной зоны }\end{array}$ & $\begin{array}{c}2008- \\
2016 \text { гг. }\end{array}$ & $\begin{array}{l}\text { Республика } \\
\text { Калмыкия, } \\
\text { Яшалтин- } \\
\text { ский район }\end{array}$ & $\begin{array}{r}1005,0 \\
\text { млн руб. }\end{array}$ & 50 & $\begin{array}{l}\text { Проектно- } \\
\text { изыскательские } \\
\text { работы }\end{array}$ \\
\hline 5 & $\begin{array}{l}\text { ООО Управ- } \\
\text { ляющая } \\
\text { компания } \\
\text { «Первая» }\end{array}$ & $\begin{array}{l}\text { Строительство } \\
\text { сети откормоч- } \\
\text { ных площадок } \\
\text { по } 500 \text { голов } \\
\text { КРС и цехов по } \\
\text { производству } \\
\text { консервов }\end{array}$ & $\begin{array}{l}\text { До } 2925 \text { т } \\
\text { мяса в жи- } \\
\text { вом весе за } \\
1 \text { цикл от- } \\
\text { корма, или } \\
1404 \text { т в } \\
\text { убойном }\end{array}$ & $\begin{array}{c}2014- \\
2016 \text { гг. }\end{array}$ & $\begin{array}{l}\text { Республика } \\
\text { Калмыкия, } \\
\text { на террито- } \\
\text { рии } 13 \text { рай- } \\
\text { онов }\end{array}$ & $\begin{array}{c}564,9 \\
\text { млн руб. }\end{array}$ & 106 & $\begin{array}{l}\text { Заключены ин- } \\
\text { вестиционные } \\
\text { договора в рам- } \\
\text { ках ежегодного } \\
\text { конкурса «Ре- } \\
\text { гионы - устой- } \\
\text { чивое развитие» }\end{array}$ \\
\hline
\end{tabular}

Примечание. Составлено автором. Рассматривая проекты ГЧП в Республике Калмыкия, следует отметить, что государственно-частное партнерство представляет собой, в наибольшей степени, возможность привлечения капитала частного сектора в виде инвестиций, а не способ реализации совместных проектов государственных и бизнес-структур.

рисков со стороны бизнес-структур и необходимости обеспечения социальных обязательств перед населением, а также эффективное управление объектами государственной собственности со стороны государственных властных структур [4; 5].

По нашему мнению, в целях улучшения бюджетной и социально-экономической эффективности по инвестиционным проектам и привлечения большего количества потенциальных инвесторов и кредиторов, органам ре- гиональной власти целесообразно применять комбинированный подход к различным источникам финансирования проекта. Для каждого конкретного проекта субъект РФ может варьировать модель финансирования, предлагаемую частному сектору в рамках ГЧП. Такой подход позволит управлять привлекательностью проекта одновременно для общества и для инвесторов.

Основными источниками финансирования проектов ГЧП могут выступать собствен- 
ный капитал инвесторов в сочетании с кредитными ресурсами частных банков. Государственная поддержка может применяться в качестве государственных гарантий, стимулирующих заинтересованность инвесторов в развитии рынка ГЧП.

В Республике Калмыкия с 2013 г. создан Инвестиционный фонд Республики Калмыкия, который представляет собой часть средств республиканского бюджета, подлежащий использованию в целях реализации на территории Республики Калмыкия инвестиционных проектов, осуществляемых на принципах государственно-частного партнерства [3].

Согласно положениям Закона Республики Калмыкия «Об Инвестиционном фонде Республики Калмыкия» бюджетные ассигнования регионального инвестиционного фонда предоставляются для реализации инвестиционных проектов на конкурсной основе. Объем бюджетных ассигнований регионального инвестиционного фонда устанавливается законом Республики Калмыкия о республиканском бюджете на очередной финансовый год и плановый период. Порядок формирования и использования бюджетных ассигнований регионального инвестиционного фонда устанавливается Правительством Республики Калмыкия.

Бюджетные ассигнования регионального инвестиционного фонда предоставляются в форме:

1) бюджетных инвестиций в объекты капитального строительства государственной собственности Республики Калмыкия, в том числе создаваемые в рамках концессионных соглашений;

2) субсидий местным бюджетам на софинансирование объектов капитального строительства муниципальной собственности, бюджетные инвестиции, осуществляемые из местных бюджетов, в том числе создаваемые в рамках концессионных соглашений;

3) финансирования разработки проектной документации на объекты капитального строительства государственной собственности Республики Калмыкия, в том числе предполагаемые к созданию в рамках концессионных соглашений;

4) субсидий местным бюджетам на софинансирование разработки проектной доку- ментации на объекты капитального строительства муниципальной собственности, в том числе предполагаемые к созданию в рамках концессионных соглашений [3].

Однако Республика Калмыкия нуждается в новых подходах в региональной инвестиционной политике, способной удовлетворить потребности в инвестициях и значительно увеличить объемы финансирования региональных инфраструктурных, инновационных и других социальных проектов, повысить качество их подготовки и эффективность управления. Регион только начинает поиск эффективных форм реализации проектов государственно-частного партнерства. При этом необходимо в правовом поле определить государство как регулятора взаимоотношений в партнерстве, а также как защитника общественных интересов и потребностей.

В законодательстве республики следует усовершенствовать правовую базу многочисленных форм государственно-частного партнерства. При вложении инвестиционных средств бизнес-структур в объекты государственной инфраструктуры инвесторы зачастую сталкиваются с нечеткостью формулировок в вопросах передачи части прав собственности от государства частному бизнесу, что приводит к высокой доле рисков при инвестировании частных средств. В целях снижения рисков необходимо законодательное закрепление за инвесторами прав на пользование объектами государственной собственности в рамках концепции ГЧП.

Развитие ГЧП предполагает юридические отношения партнеров, закрепленные в нормативно-правовых актах и четко согласованные. Однако в отношениях между государством и бизнесом использование принципа свободы договора противоречит бюджетному законодательству.

Деятельность органов исполнительной власти региона в рамках реализации ГЧП со всеми заинтересованными сторонами, направленная на реализацию инновационной стратегии развития Республики Калмыкия, должна привести к формированию принципиально новой модели регионального развития.

Вместе с усилением административных методов регулирования инвестиционного процесса, большое внимание должно быть уде- 
лено социально-психологическим факторам (факторы инвестиционных ожиданий со стороны потребительского рынка), недооценка которых приводит не только к снижению эффективности мер по реализации стратегии, но и к возникновению психологических барьеров между участниками по разработке и реализации инвестиционной стратегии. В связи с этим на всех этапах реализации стратегии, в частности, функционирования обновленного образовательного кластера, будет происходить наращивание материально-технической и методологической базы региона [7].

В Республике Калмыкия управление государственно-частным партнерством осуществляют различные подразделения органов исполнительной власти, наделенные таковыми полномочиями. Но в настоящее время действия уже сформированных подразделений в регионе не являются скоординированными, так как отсутствует единая стратегия правительства региона в области развития государственно-частного партнерства. Организационная рассредоточенность свидетельствует о проблемах в управлении сферой государственно-частного партнерства в Республике Калмыкия и в ближайшем будущем в связи с отсутствием механизма развития государственно-частного партнерства как на уровне региона, так и на уровне муниципальных образований.

Такое положение затрудняет развитие партнерских отношений между бизнесом и властью и препятствует внедрению новых форм взаимодействия, а следовательно, и развитие самого института государственно-частного партнерства.

В целях прозрачности механизма взаимодействия органов государственной власти и предпринимательских структур необходимо разработать и законодательно закрепить более четкие стандарты конкурсных процедур отбора и документаций инвестиционных проектов ГЧП и контроля за их реализацией. При этом государство будет иметь возможность превратиться в полноценного квалифицированного заказчика проектов ГЧП, а бизнес, в свою очередь, получит необходимый ему опыт.

Помимо проблем законодательного характера, можно выделить организационные проблемы, с которыми сталкивается инвес- тор при принятии решения об участии в ГЧП. Во-первых, отсутствуют примерные виды соглашений и методические рекомендации по заключению соглашений в отношении определенных форм инвестиционной деятельности и (или) применительно к различным сферам реализации соглашения. Во-вторых, отсутствует единая специализированная структура по развитию и управлению ГЧП.

Международный и отечественный опыт функционирования ГЧП позволяет сделать вывод о том, что необходимо институциональное закрепление ГЧП. Учитывая данный факт, автором предлагается учредить новую институциональную структуру ГЧП - Региональный центр развития ГЧП (далее - Центр), целью которого будет объединение профессионального сообщества, разработка методов осуществления проектов на основе ГЧП и обобщение опыта текущей реализации указанных проектов. В наблюдательный совет данного Центра необходимо включить как представителей государства, так и коммерческих структур (см. рисунок).

Являясь основным оператором и координатором проектов ГЧП, Центр должен проводить анализ прямых и косвенных прогнозных затрат проекта, в том числе капитальных затрат и текущих расходов; реальной налоговой ставки и прогнозного уровня инфляции; анализ и величину рисков.

Центр должен работать исключительно с государственным сектором и в основном выполнять функции разработки проектов как на стадии технических аспектов, так и бизнеспланов. Штат сотрудников Центра должен состоять из экспертов государственного и частного секторов, которые обладают умениями и навыками в области проектного финансирования (финансы, правовые вопросы и т. п.).

В целях систематизации и координации деятельности по реализации государственной политики развития ГЧП, а также совместного поиска потенциальных инвесторов для реализации приоритетных проектов и программ Центр должен осуществлять работу по расширению и регламентации связей между представителями деловых и профессиональных сообществ.

Кроме регионального центра развития институциональной структурой развития ГЧП 


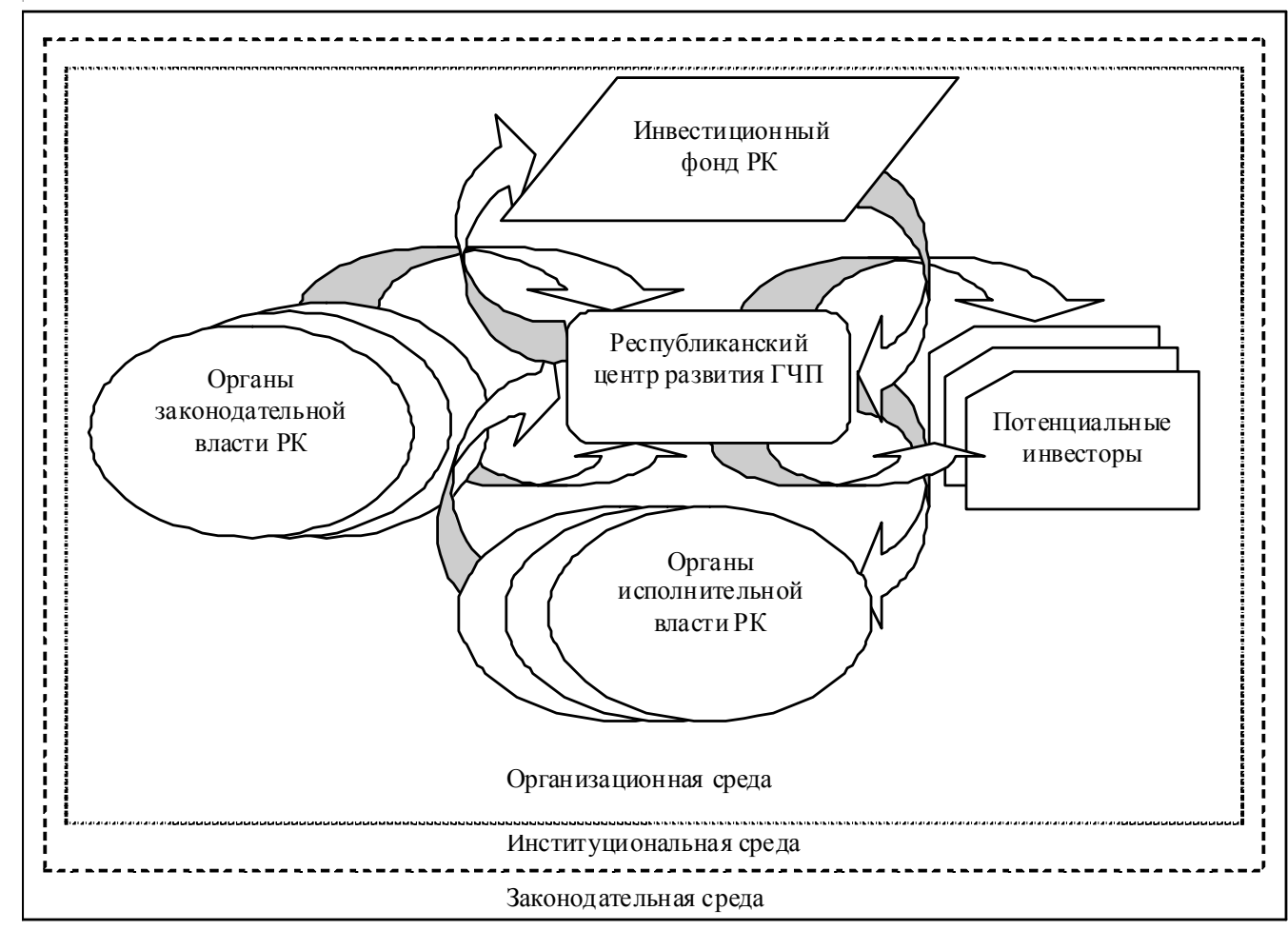

Рисунок. Схема взаимодействия Регионального центра развития ГЧП с субъектами ГЧП Примечание. Составлено автором.

может стать межрегиональная корпорация развития, основное назначение которой должно состоять в развитии всех отраслей экономики, а также в выстраивании эффективной системы взаимодействий между органами государственной и муниципальной власти, инвесторами и финансовыми институтами. Данная корпорация развития может быть создана в форме публичного акционерного общества с участием в ее капитале доли субъектов Российской Федерации, желающих участвовать в межрегиональном развитии.

Таким образом, несмотря на сложности, существующие сегодня, ГЧП является одним из перспективных инструментов финансирования проектов, который включает в себя выгоды как для республики в виде улучшения бюджетной и социально-экономической эффективности инфраструктурных проектов, так и для частного сектора путем обеспечения гарантированных денежных потоков на протяжении длительного времени. Роль региональных органов власти при существенном дефиците собственных средств и необходимости привлечения частных инвесторов должна заключаться в предоставлении государ- ственных гарантий с целью стимулирования заинтересованности инвесторов в развитии рынка ГЧП.

\section{СПИСОК ЛИТЕРАТУРЫ}

1. Буянова, М. Э. Меры по регулированию дифференциации социально-экономического развития регионов ЮФО / М. Э. Буянова, В. В. Васильев // Современные тенденции развития науки и технологий : материалы XVIII Междунар. науч.-практ. конф. - Белгород : Агентство перспективных научных исследований, 2016. - С. 12-17.

2. Васильев, В. В. Межбюджетные отношения как основа современной региональной политики России / В. В. Васильев // Вестник Волгоградского государственного университета. Серия 3 , Экономика. Экология. - 2016. - № 2 (35). - С. 35-43.

3. Закон Республики Калмыкия от 26.12.2012 № 398-IV-3 «Об Инвестиционном фонде Республики Калмыкия. - Доступ из справ.-правовой системы «Гарант».

4. Некоторые аспекты взаимодействия государственных, научных и бизнес-структур в системе региональной экономики (на материалах Республики Калмыкия) / Э. И. Мантаева, И. В. Слободчикова, В. С. Голденова, Б. В. Джамбинов // Экономи- 
ка и менеджмент в условиях нелинейной динамики. - СПб., 2017. - С. 285-309.

5. Оценки эффективности института ГЧП и рисков проектов, реализуемых на основе принципов ГЧП / Л. С. Шаховская, Е. Г. Попкова, И. А. Морозова, У. А. Позднякова // Современные проблемы науки и образования. - 2014. - № 6. - С. 447.

6. Теоретико-методологические основы секторно-сбалансированного развития региона в условиях постиндустриализации / Д. П. Фролов, И. В. Стратулат, И. А. Соловьева, М. М. Бабкин, Д. А. Шелестова // Бизнес. Образование. Право. Вестник Волгоградского института бизнеса. 2015. - № 1 (30). - С. 106-110.

7. Указ Главы Республики Калмыкия от 27 марта 2014 г. № 37 «Об утверждении Инвестиционной стратегии Республики Калмыкия до 2025 года». - Доступ из справ.-правовой системы «Гарант».

\section{REFERENCES}

1. Buyanova M.E., Vasilyev V.V. Mery po regulirovaniyu differentsiatsii sotsialnoekonomicheskogo razvitiya regionov YuFO [Regulation of Differentiation of Socio-Economic Development of the Regions of Southern Federal District]. Sovremennye tendentsii razvitiya nauki $i$ tekhnologiy: materialy XVIII Mezhdunar. nauch.prakt. konf. [Modern Trends in the Development of Science and Technology: Proceedings of the $18^{\text {th }}$ International Scientific-Practical Conference]. Belgorod, Agentstvo perspektivnykh nauchnykh issledovaniy, 2016, pp. 12-17.

2. Vasilyev V.V. Mezhbyudzhetnye otnosheniya kak osnova sovremennoy regionalnoy politiki Rossii [Inter-Budgetary Relations as a Basis of Modern Regional Policy of Russia]. Vestnik Volgogradskogo gosudarstvennogo universiteta. Seriya 3, Ekonomika. Ekologiya [Science Journal of Volgograd State
University. Global Economic Systsem], 2016, no. 2 (35), pp. 35-43.

3. Zakon Respubliki Kalmykiya ot 26.12.2012 № 398-IV-Z «Ob Investitsionnom fonde Respubliki Kalmykiya [The Law of the Republic of Kalmykia of December 26, 2012 no. 398-IV-Z “On Investment Fund of the Republic of Kalmykia"]. Access from Reference Legal System "Garant".

4. Mantaeva E.I., Slobodchikova I.V., Goldinova V.S., Dzhambinov B.V. Nekotorye aspekty vzaimodeystviya gosudarstvennykh, nauchnykh i biznes-struktur $\mathrm{V}$ sisteme regionalnoy ekonomiki (na materialakh Respubliki Kalmykiya) [Some Aspects of the Interaction between State, Scientific and Business Structures in the System of Regional Economy (the Case of the Republic of Kalmykia)]. Ekonomika $i$ menedzhment $v$ usloviyakh nelineynoy dinamiki [Economy and Management in the Conditions of NonLinear Dynamics]. Saint Petersburg, 2017, pp. 285-309.

5. Shakhovskaya L.S., Popkova E.G., Morozova I.A., Pozdnyakova U.A. Otsenki effektivnosti instituta GChP i riskov proektov, realizuemykh na osnove printsipov $\mathrm{GChP}$ [Evaluation of the Effectiveness of the Institute of PPP and Risks of Projects Based on PPP Principles]. Sovremennye problemy nauki i obrazovaniya, 2014, no. 6, p. 447.

6. Frolov D.P., Stratulat I.V., Solovyeva I.A., Babkin M.M., Shelestova D.A. Teoretikometodologicheskie osnovy sektorno-sbalansirovannogo razvitiya regiona $\mathrm{v}$ usloviyakh postindustrializatsii [Theoretical and Methodological Foundations of the Sector-Balanced Development of the Region in Terms of Post-Industrialization]. Biznes. Obrazovanie. Pravo. Vestnik Volgogradskogo instituta biznesa, 2015, no. 1 (30), pp. 106-110.

7. Ukaz Glavy Respubliki Kalmykiya ot 27 marta 2014 g. № 37 «Ob utverzhdenii Investitsionnoy strategii Respubliki Kalmykiya do 2025 goda» [The Decree of the Head of the Republic of Kalmykia of March 27, 2014 no. 37 “'On Approval of the Investment Strategy of the Republic of Kalmykia till 2025"]. Access from Reference Legal System "Garant”.

\section{Information About the Author}

Kermen M. Maksimova, Postgraduate Student, Department of State and Municipal Management and Law, Kalmyk State University named after B.B. Gorodovikov, Pushkina St., 11, 358000 Elista, Russian Federation, kermen_maksimova@mail.ru.

\section{Информация об авторе}

Кермен Михайловна Максимова, аспирант кафедры государственного и муниципального управления и права, Калмыцкий государственный университет имени Б.Б. Городовикова, ул. Пушкина, 11, 358000 г. Элиста, Российская Федерация, kermen_maksimova@mail.ru. 